\title{
PROPRANOLOL IN THE TREATMENT OF SUBGLOTTIC HAEMANGIOMA
}

\author{
Amir HALILBAŠIĆ, Nešad HOTIĆ, Edin HUSARIĆ, Amela PAŠIĆ, Sanimir SULJENDIĆ
}

Department of Paediatrics University Clinical Centre Tuzla

Tuzla, Bosnia and Herzegovina

Corresponding author:

Amir Halilbašić

Department of Paediatrics

University Clinical Centre Tuzla

75000 Tuzla

Bosnia and Herzegovina

hamir@bih.net.ba

Tel.: + 38761259016

Fax.: + 38735303700

Received: March 27, 2014

Accepted: June 11, 2014

Copyright (C) 2014 by University Clinical Centre Tuzla. E-mail for permission to publish: paediatricstoday@ukctuzla.ba

\begin{abstract}
Objective - Subglottic infantile haemangioma (SGH) is a rare but potentially life-threatening disease. We describe a case of successful treatment with propranolol of a severely respiratory compromised 2-month-old infant with an obstructing SGH. Case report - A fullterm 2-month-old male infant, weighing $4.8 \mathrm{~kg}$, without cutaneous haemangioma, presented with stridor, dyspnoea, oxygen desaturation and tachycardia. Contrast enhanced neck-chest CT scan was used to diagnose a $5 \times 7 \times 7 \mathrm{~mm}$ subglottic elliptic lesion, referable to SGH with a free air column of $2 \mathrm{~mm}$ wide. Per oral propranolol was started with a therapeutic dosage of $2 \mathrm{mg} / \mathrm{kg} /$ day in 3 administrations. On the second day of treatment there was rapid clinical improvement of the infant with withdrawal of respiratory symptoms. After treatment, the control CT showed the regression of SGH. Twenty-one months later the patient is without respiratory symptoms. Conclusion - Propranolol medical treatment should be considered in all subglottic haemangioma, even in acute cases.
\end{abstract}

Key words: Subglottic haemangioma - Propranolol - Laryngotracheal stenosis.

\section{Introduction}

Infantile haemangiomas $(\mathrm{IH})$ are common benign tumours in infancy, affecting 5\%$10 \%$ of all infants, and up to $30 \%$ of premature newborns and chorionic villus sampling exposed infants $(1,2)$. Although $85-90 \%$ of all IH eventually undergo spontaneous involution, they can still cause disfigurement and serious complications depending on their location, such as laryngeal infantile haemangioma (LIH). Infantile subglottic haemangiomas are rare causes of airway obstruction. At birth, IH may not be apparent or may appear as flat circumscribed lesions with telangiectatic vessels on the surface. Within the first weeks of life, IH enter a phase of rapid growth, with superficial and/or deep components, which lasts usually 3 to 6 months, and sometimes up to 24 months (3). The conventional approach in complicated cases is to use systemic corticosteroid therapy as the first-line treatment, and then interferon or vincristine as second- or third-line therapeutic agents. Unfortunately, each treatment option has limited therapeutic benefits, with its own side-effect profile and risks (4). In 2008, Léauté-Labrèze and colleagues described their serendipitous observation of an anti-proliferative effect of propranolol on $\mathrm{IH}$ (5). Since it was first reported as therapy for $\mathrm{IH}$, propranolol has become the first choice therapy for complicated IH. Various therapeutic options have been utilized for treat- 
ment of LIH, including tracheotomy, open surgical excision, laser ablation, intralesional steroid injection, systemic steroids, and now oral propranolol (6). We describe a case of successful treatment with oral propranolol, of a stridulous 3-month-old infant with an obstructing subglottic haemangioma.

\section{Case report}

A full-term 2-month-old male infant, weighing $4.8 \mathrm{~kg}$, without cutaneous haemangioma, presented to our institution with stridor, dyspnoea, oxygen desaturation (90\%) requiring oxygen support of $1.5 \mathrm{l} / \mathrm{min}$, and a heart rate of 176 beats per minute. He had already undergone chest X-ray, which was normal, about 25 days before, at the onset of respiratory symptoms, and received pharmacological empiric therapy for acute laryngitis. His mother declined the proposed diagnostic fibrobronchoscopy. A neck-chest CT scan, with transverse plane images, revealed a contrast-enhancing $5 \times 7 \times 7 \mathrm{~mm}$ subglottic elliptic lesion, referable to $\mathrm{SGH}$ with a free air laryngeotracheal column $2 \mathrm{~mm}$ wide. There was a grade III subglottic obstruction, according to the Myers-Cotton subglottic stenosis grading scale (7).

After echocardiography and cardiologist exam, we started per oral propranolol therapy with slow dosage advancement (first day dose was $0.5 \mathrm{mg} / \mathrm{kg} / \mathrm{day}$, second day 1 $\mathrm{mg} / \mathrm{kg} /$ day in 3 administrations) until we reached the therapeutic dose of $2 \mathrm{mg} / \mathrm{kg} /$ day in 3 administrations on the third day. In therapy introduction we carefully monitored blood pressure, heart rate and blood glucose, which remained within normal ranges. On the second day of propranolol therapy, the child's respiratory symptoms rapidly and dramatically improved, with no stridor and dyspnoea. After 14 days of therapy, the infant was discharged home with no respiratory

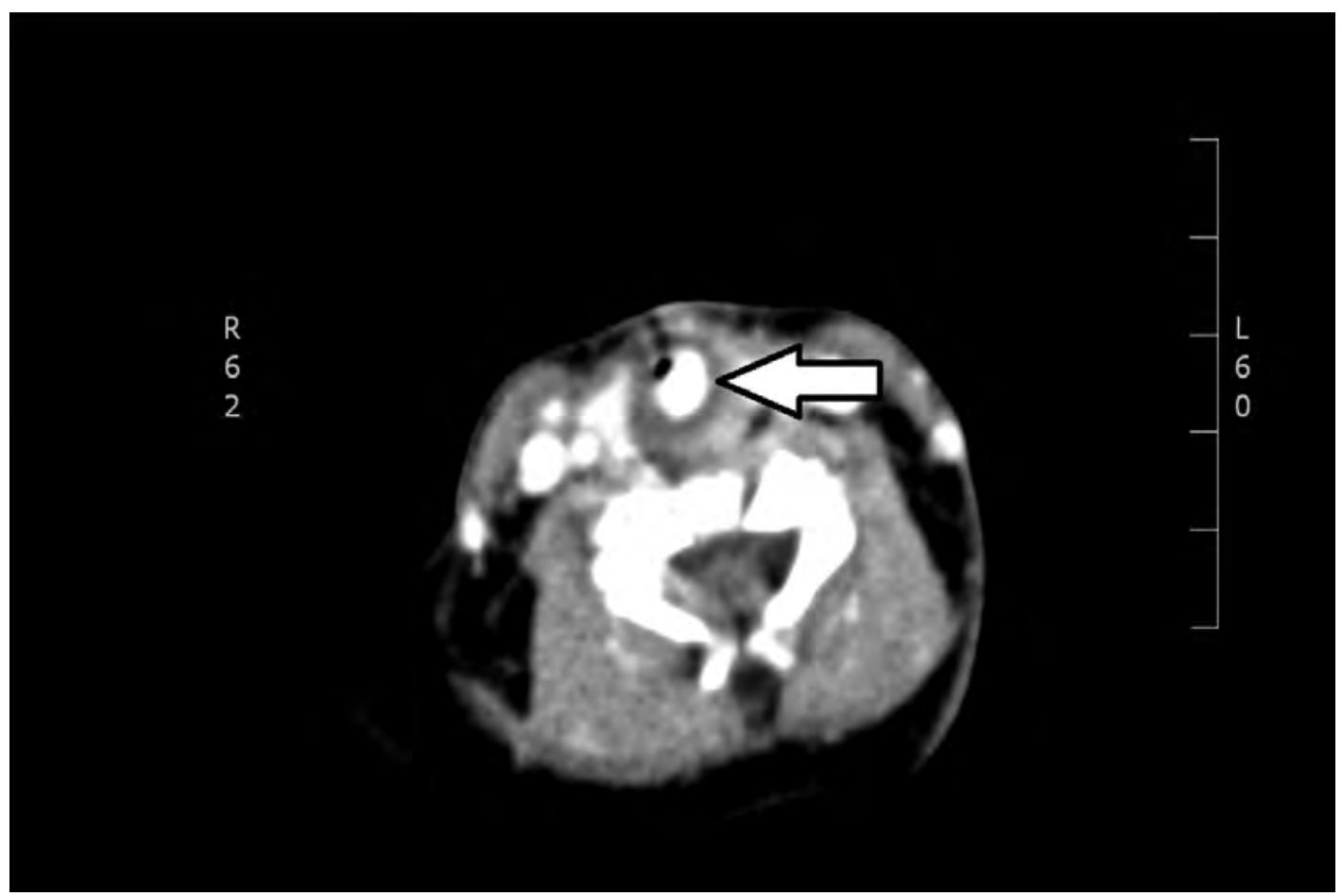

Fig. 1 CT of the neck before treatment. 


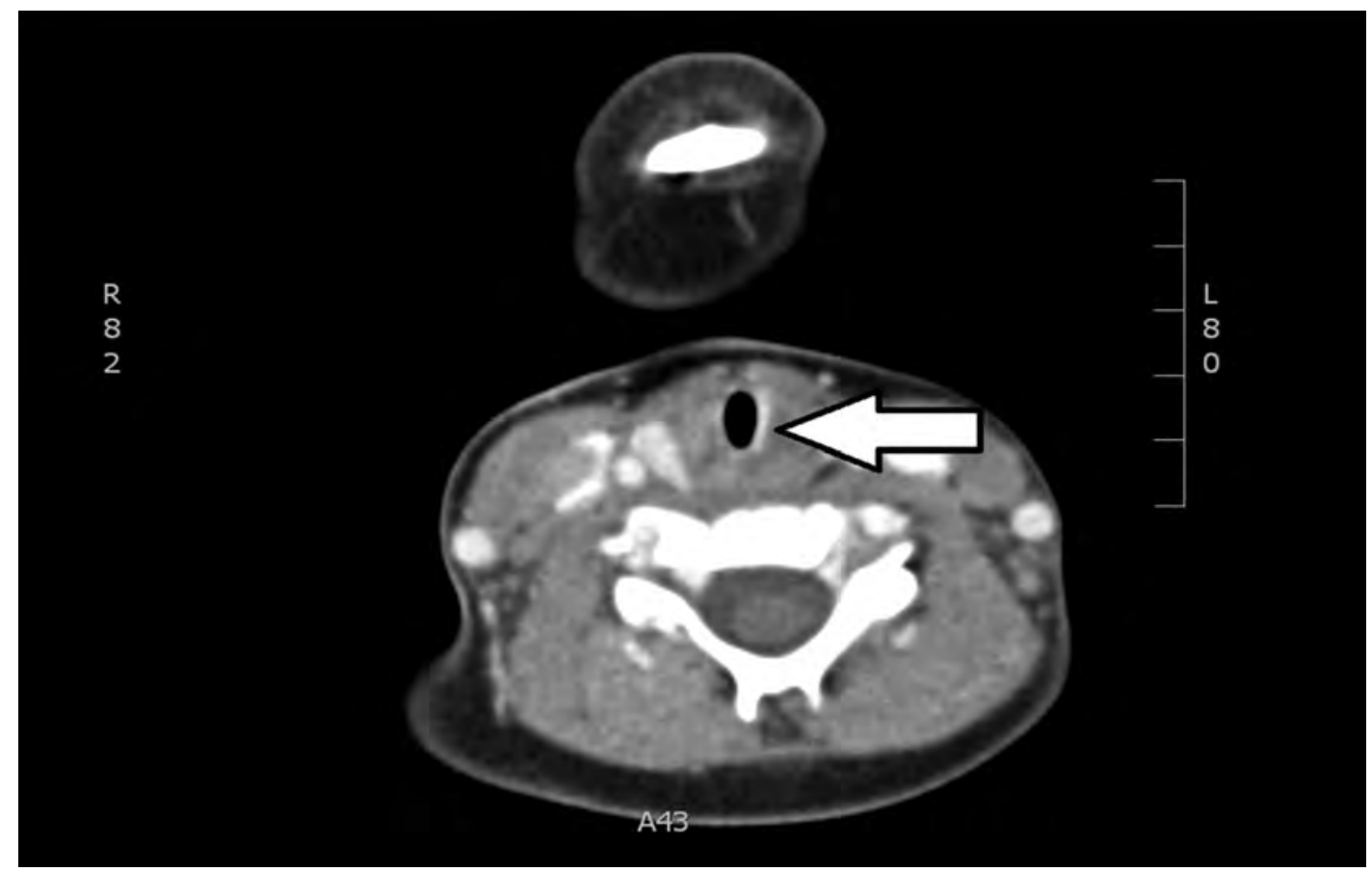

Fig. 2 CT of the neck after treatment.

symptoms. The total length of propranolol therapy was 8 months, with monthly dosage adjustments. One month after the propranolol therapy ended, control neck CT scan revealed a $1.5 \mathrm{~mm}$ wide SGH in significant regression and without any airway space obstruction (Fig. 2). At the moment, the boy is 21 months of age and has no respiratory symptoms.

\section{Discussion}

SGH is a rare but potentially life-threatening disease. Approximately 50\% of these children also have cutaneous haemangioma, with a beard pattern distribution (8). Since it was first reported in the therapy of $\mathrm{IH}$, propranolol has become the first choice of therapy for complicated IH. Various therapeutic options have been utilized for treatment of LIH, including tracheotomy, open surgical excision, laser ablation, intralesional steroid injection, systemic steroids, and now oral propranolol
(6). The proposed mechanism for the action of propranolol is that it induces vasoconstriction and capillary endothelial cell apoptosis (8). Regulators of IH growth and involution are still poorly understood, but it has been demonstrated that, during the growth phase, 2 major proangiogenic factors are involved, that is, the basic fibroblast growth factor (bFGF) and the vascular endothelial growth factor (VEGF), which are present in situ, but also in the blood and urine. One hypothesis to explain the endothelial cell apoptosis in capillary IHs involves the expression of intercellular adhesion molecule 1 on the cell surface, but an alternative possibility may be the loss of stimulatory factors, such as VEGF (3). SGH is usually not evident at birth, but grows rapidly during the first year of life: the proliferation phase begins at around 1-2 months of age, causing intermittent airway obstruction, which is more evident during periods of agitation and crying. The most common symptoms are stridor (usually biphasic but more prominent during inspiration), respira- 
tory distress, cough, hoarseness, dysphagia, vomiting and haemoptysis (8). Diagnosis is the main challenge, especially in an unstable patient with respiratory distress. As a first diagnostic step, neck-chest $\mathrm{X}$-ray can determine the location and the symmetry or asymmetry of the subglottic narrowing. Neck-chest CT with multiplanar reconstruction represents the main method of investigation through imaging, revealing the precise site, contrast enhancement and shape of the SGH (8). Multiple techniques have been utilized in the treatment of SGH and no single option is acceptable for all patients (9). Treatment should aim to reduce the size of the $S G H$, resolve symptoms and maintain stable lesion involution. Carefully administered, propranolol may demonstrate efficacy as a first-line agent in most cases, including severely respiratory compromised cases, avoiding surgery, tracheostomy, prolonged steroids, or as treatment of a diffuse and unresectable disease $(6,9,10$, 11). However, some lesions may be resistant to propranolol and require surgery or longterm steroids (12).

\section{Conclusion}

On the basis of the case we reported and other reports, propranolol medical treatment should be considered in all SGH cases, in place of procedures which have previously resulted in higher mortality and morbidity. We now believe the dramatic response to propranolol allows treatment in the acute setting, even with high grade subglottic stenosis.

Authors' contributions: Conception and design: $\mathrm{AH}, \mathrm{EH}$; Acquisition, nalysis and interpretation of data: AH, SS, AP; Drafting the article: AH, AP; Revising it critically for important intellectual content: $\mathrm{NH}, \mathrm{EH}$ AP.

Conflict of interest: The authors declare that they have no conflict of interest.

\section{References}

1. Garzon MC, Frieden IJ. Hemangiomas: when to worry. Pediatr Ann 2000;29(1):58-67.

2. Drolet BA, Swanson EA, Frieden IJ; Hemangioma Investigator Group. Infantile hemangiomas: an emerging health issue linked to an increased rate of low birth weight infants. J Pediatr. 2008;153(5):712-5.

3. Sans V, de la Roque ED, Berge J, Grenier N, Boralevi F, Mazereeuw-Hautier J et al. Propranolol for severe infantile hemangiomas: follow-up report. Pediatrics. 2009;124(3):423-31.

4. Buckmiller LM, Munson PD, Dyamenahalli U, Dai Y, Richter GT. Propranolol for infantile hemangiomas: early experience at a tertiary vascular anomalies center. Laryngoscope. 2010;120(4):676-81.

5. Léauté-Labrèze $C$, Dumas de la Roque E, Hubiche T, Boralevi F, Thambo JB, Taïeb A. Propranolol for severe hemangiomas of infancy. N Engl J Med. 2008;358(24):2649-51.

6. Raol N, Metry D, Edmonds J, Chandy B, Sulek M, Larrier D. Propranolol for the treatment of subglottic hemangiomas. Int J Pediatr Otorhinolaryngol. 2011;75(12):1510-4.

7. Myer CM 3rd, O'Connor DM, Cotton RT. Proposed grading system for subglottic stenosis based on endotracheal tube sizes. Ann Otol Rhinol Laryngol. 1994;103(4 Pt 1):319-23.

8. Loizzi M, De Palma A, Pagliarulo V, Quaranta N. Propranolol as first-line treatment of a severe subglottic haemangioma. Eur J Cardiothorac Surg. 2013;43(1):187-9.

9. Javia LR, Zur KB, Jacobs IN. Evolving treatments in the management of laryngotracheal hemangiomas: will propranolol supplant steroids and surgery? Int J Pediatr Otorhinolaryngol. 2011;75(11):1450-4.

10. Bajaj Y, Kapoor K, Ifeacho S, Jephson CG, Albert DM, Harper JI, et al. Great Ormond Street Hospital treatment guidelines for use of propranolol in infantile isolated subglottic haemangioma. J Laryngol Otol. 2013;127(3):295-8.

11. Peridis S, Pilgrim G, Athanasopoulos I, Parpounas K. A meta-analysis on the effectiveness of propranolol for the treatment of infantile airway haemangiomas. Int J Pediatr Otorhinolaryngol. 2011 ;75(4):455-60.

12. Leboulanger N, Fayoux P, Teissier N, Cox A, Van Den Abbeele T, Carrabin L, et al. Propranolol in the therapeutic strategy of infantile laryngotracheal hemangioma: A preliminary retrospective study of French experience. Int J Pediatr Otorhinolaryngol. 2010;74(11):1254-7. 